\title{
Futures Thinking: Strategy Used by Health Care Organization to Survive Economic Collapse During the Great Recession of 2008
}

\author{
Steven Walker \\ Department of Leadership and Human Resources, National University, San Diego, USA
}

Email address:

swalker@nu.edu

\section{To cite this article:}

Steven Walker. Futures Thinking: Strategy Used by Health Care Organization to Survive Economic Collapse During the Great Recession of 2008. American Journal of Management Science and Engineering. Vol. 5, No. 5, 2020, pp. 56-61. doi: 10.11648/j.ajmse.20200505.11

Received: September 30, 2020; Accepted: October 23, 2020; Published: November 4, 2020

\begin{abstract}
This case tells how a leader of a health care institution used systems thinking as a foresight tool to help survive the Great Recession of 2008. The original study on which this case is based sought to understand the essence of leaders' interior response to the Great Recession of 2008 with regard to sustainability and leadership. The impact of the Great Recession of 2008 on organizational leaders with regards to sustainable policy making was examined by addressing: (a) how sustainability is defined, (b) the philosophy that underlies sustainable thinking within organizations, (c) leadership elements that are important to sustainable implementation, and (d) how system breaking points provide the opportunity for sustainable transformation. Due to the leader's systems thinking perspective, several behavior themes emerged. Organizational policies were then developed to help institutionalize these behaviors, and which prepared the organization for a successful and sustainable response to the oncoming catastrophe. Strategic management strategies, supporting futures thinking, ultimately guided and stabilized the organization throughout this economic crisis, effectively leading to future growth.
\end{abstract}

Keywords: Foresight Methodology, Leadership, Systems Thinking, Great Recession, Health Care

\section{Introduction}

Author's note: while the leader whose story is presented here is an actual leader at a health care institution in the Pacific Northwest, his name and the name of his organization have been changed to protect his privacy. A pseudonym was chosen for the organizational leader and is used throughout this paper.

On September 29th, 2008, the Dow Jones Industrial Average dropped 774 points. At the time, this was the record for a single day point drop of the stock market in United States history. This was only the beginning. The months that followed created an economic collapse the United States hadn't seen since the Great Depression. With the economy in a tailspin, organizations around the country were required to face rapidly changing environments or be forced to dissipate and dissolve. Hundreds of organizations would fail. This case will examine one organization that survived. Specifically, this case examines a large health care institution in Portland OR, and the use of the foresight methodology of systems thinking by the organization's President, to enable the development and implementation of organizational policies that would sustain the organization through the rapid changes brought on by the Great Recession of 2008 .

\section{Tim's Story}

\subsection{Internal Response to the Crisis}

Tim (pseudonym) was the President of a large healthcare organization in Portland, Oregon. In addition to being a Medical Doctor of neuroscience, Tim was also the head of the academic department at a research institution.

I asked Tim about the day Lehman Brothers collapsed and the Dow Jones plunged 774 points, and whether or not those events stood out to him. Tim stated that he remembered those two days in September vividly, but that he was not surprised by them. He added that he had seen them coming for some time. He recalled that his concern on those two days were more in regard to the rest of the country than for his particular field or organization. Tim said he was aware there would be 
changes in the overall economic environment, but he was never worried about the survival of his institution.

"My thoughts were always more oriented towards how we were going to adapt to the new environment rather than whether we were going to survive. Which was probably different than some people. My mind was always focused on the fact that this was a new landscape and what was I going to do."

Tim said he believed the "new landscape" that the economic collapse would create would be that of much tighter resources and less endowment funds. Tim recalled that the months following the market collapse were ones where he tried to foresee and understand the new essence of the economy. Tim also said that, as a leader, it was a time to look at the collapse as an opportunity to restructure the organization, get leaner and cut unnecessary programs, and interconnect and partner with other organizations and the community.

"We took that opportunity and did a relook at the organization and did some redesigning and reorganization.

Did some strategic planning. Went through a lean process. I think it served as a catalyst for us to do even more partnership formation than we had done before. I think if you are in a time of scarce resources, and especially capital resources, if you do things in partnership you can reduce your capital allocations."

Tim gave an example of a building that his institution was in the process of building at the time of the collapse. Instead of ending the project and losing money, they partnered with several other institutions, finished the project, and are now sharing the use of it. He added that it worked out well because it is now one of the most utilized buildings in the state:

"I think the recession raised the awareness that this was going to be an environment of scarce resources for a long time. So the recession really was the catalyst that catapulted our thinking into how do we form more partnerships, how do we leverage them, where else can we do this, etc."

\subsection{Leader and Organizational Behavior}

Tim mentioned that as a leader he felt it was important to be very visible, communicative, truthful, and transparent. Tim cited public town hall meetings he organized that allowed him the ability to establish dialogue with the public. "We held town hall forums. We tried to be very clear about what the ramifications were to our employees. We shared our financial data. We were very public about our plans."

Tim said the recession experience also forced him to get back to his core values, both personally and professionally. He said it forced him to ask professionally what it was that made them stand out from the rest and what gave them the sustainable advantage over their competition.

"Where is it that you create value? Where is your niche? Where is your need in this society? And I think if you focus on what that need is rather than how much money you can make and if you focus on the long-term meeting that need rather than the financial return [then you will succeed]. I am a true believer in knowing what your mission is and what your core being is and being passionate about that and staying true to that."

I asked Tim if he could take me into some of the important values that his organization held.

"We have a four-pronged mission. And you can ask anybody. They are: healing, teaching, discovery, and outreach. So basically, patient care, education, research, and community service. That is what it is and what we do. And the values are quality, transparency, service excellence, and diversity. Those are the missions and values. I think if you pursue those and it will make the financials work."

Tim added that he believed his organization is successful and sustainable because they stick to the organization's core values and beliefs. He felt that, as a leader, it was important to communicate that fact to the organizational stakeholders throughout the crisis.

Tim said the communicative and transparent nature of his organization during the crisis was tied to the organization's mission and values. During the crisis, Tim felt it was extremely important to stay true to them. He added that he always felt their success had to do with their transparency, truthfulness, and good communication with both the public and their employees. This resulted in increases in joint partnerships.

"In fact, instead of starting a new school of public health we are starting a joint school of public health with another organization. We each have strengths in different areas, so instead of having to recruit, why not just come together and do it jointly? It became a step towards our interconnectedness."

Tim reiterated several times how important the recession was in influencing his organization into more interconnected partnerships. Tim continued to comment back to the partnerships that were created because of the recession. He also said that he felt that it strengthened his organization overall.

\subsection{Ability to Sustain Through Crisis}

Tim and I then switched topics and began to discuss sustainability. Tim started by saying that he saw his organization as made up of numerous smaller components and programs. Tim mentioned that he believed that his organization was sustainable not only because of the field it was in, but because of the programs his institution runs. So, for Tim to address the sustainability of the overall institution, he had to first address the sustainability of each program. Tim stated that, before he added a program or when he personally analyzed whether or not to keep a program running, he looked at whether it was relevant, culturally acceptable, and had firm financial support:

"If you look at every program and as far as whether it is sustainable or not, there needs to be a compelling reason for the program. So asking, is this program - and sure, it could be a good program - but is there any real need for it? If there are ten other places in the state that train students to do this and they are closer to where the students live or whatever, then is it really relevant for our organization to be doing it? So I think if you want something to be sustainable 
you have to ask if there is really a reason for you to be doing it."

Adding to that was the underlying reality that the program had to have financial support to keep it afloat. "Just because it is a wonderful program, if it doesn't have enough financial support then it will result in a drain on the other aspects of the institution and ultimately a threat to the overall mission."

Tim said that he saw the recession having a large impact on his perspective of sustainability, in that it forced him to take a closer look at all the programs he had currently running and start to prune back and lean out some of them. Tim said his organization's pruning of programs was the catalyst for interconnections and partnerships with other institutions, which Tim believed significantly increased following the recession.

"In some instances, it comes down to asking, 'instead of doing this alone should we be doing it with someone else?'

We used to not have enough rehab beds; we didn't have an extensive rehab program so basically; we send our rehab patients to the other rehab center now. We can use that capacity for other things. That is a good arrangement. There is a community resource that we can help support by doing that and allow us to have an alternative and perhaps better-fit use of that space."

\subsection{Into the Next Decade}

Before closing, Tim had a few more thoughts to share regarding leadership moving forward into the next decade. He mentioned that he strongly felt that both adaptability and flexibility would be essential characteristics for leaders to have going forward in the next five to ten years:

"The crystal ball is the murkiest, at least in this industry, as it has ever been. Healthcare transformation is going to occur, but no one knows what it really is. We know that margins are going to be reduced, because there going to be great pressure on price. Among the chief reasons for that are that the government is continuing to be a larger and larger buyer of healthcare. So you have to have [leaders] that accept that and understand that's the case. That don't think that's unrealistic. And are committed to finding those solutions. I always say that we live on the knife-edge of innovation because we develop new research, new techniques, new treatments, new training, and we disperse those. Our whole essence here is about innovation. And that will be true now than ever before."

Tim ended by saying that he thought the recession was positive for his organization, in that it sparked a transformation in the healthcare system that was much needed.

"I do think that the healthcare transformation was something our nation was going to have to go through at some point. This is a growing pain. We cannot continue the same amount of care in the same model forever. That is economically unsustainable. So, what the Great Recession has done has brought that into focus and it might mean that we as a nation will need to deal with it sooner than we might have otherwise. So, it is something that needs to be dealt with. It was inevitable. The timetable has probably been moved up."

\section{Discussion}

\subsection{Systems Thinking as a Foresight Methodology}

Some authors contend that organizations, similar to biological entities, are naturally inclined to look to the future for hidden threats and use the information to prepare for safety [1]. In leadership, this characteristic is known as foresight. Foresight has been defined as "the systematic consideration of, and action on, the future" [2]. The goal of foresight by leaders is to plan and prepare for the future and use every opportunity available to shape the future to the organization's advantage [2].

In the story Tim shared, he interpreted the breaking points as highly interconnected and complex phenomena. While the collapse of Lehman and the decline in the stock market could be considered by some to reside solely in the financial markets, Tim saw the crisis as a series of interconnected events. In fact, for Tim the breaking points were expected due to his foresight and awareness of the interrelated sets of problems leading up to the crisis. This awareness led to understanding that an impact would be felt throughout the economy, regardless of whether or not the collapse had begun in the financial sector.

Several breaking points were mentioned by Tim during his interview. The examples of the Lehman Brothers collapse on September 15th, 2008, and the Dow Jones plunge on September 29th, 2008, were both provided as examples for Tim.

These interpretations of the breaking points as having consequences and impacts throughout the economy are characteristic of systems thinking. Someone who holds a systems thinking viewpoint understands the relationships in and between systems, and how, when those relationships change, the entire structure of the system will change with them [3-7]. Tim foresaw, through a systems thinking approach, that the economic collapse would translate into a "new landscape" or new environment.

Meadows used the economic system as an example of a complex open system consisting of multiple feedback loops and time lags residing within the loops and between other connected systems [5]. The system thinking paradigm understands how changes in elements or relationships within a system can impact the entire structure of a system [5]. Meadows argued that this was a foundational paradigm necessary for sustainability within the context of organizations $[5]$.

Tim was keenly aware of oncoming chaos with regard to the recession. There was an understanding that, while the initial collapse was concentrated in the financial sector, the entanglement of relationships in the economic system would eventually create impact within various other sectors and fields across the economy, including health care. Tim's internal construction and interpretation of the breaking points within the foresight methodology of systems thinking resulted 
in three behavioral themes, which are discussed in the following section.

\subsection{Institutionalizing Behavior Through Organizational Policy}

While Prigogine and Stengers [8] wrote about the consequences of bifurcation points in natural systems, Kirk [9] adapted the idea into the context of social systems, specifically organizations. Wilber [10] saw breaking points as moments where the consciousness and psychology of individuals could be shifted and self-transcended into a new and more sustainable state of awareness. From this analysis, three behavioral themes emerged from the collected data. The systems thinking interpretation of the recession by Tim led to: a) an immediate increase in communication and dialogue, b) an increase in collaboration and relationship awareness, and c) a greater appreciation for organizational values. Each of these themes is more fully articulated in the following subsections.

\subsection{Dialogue and Communication}

Tim mentioned a significant increase in dialogue and communication that followed the bifurcation points and continued throughout the recession. This trait of dialogue, communication, and transparency was one that echoed repeatedly in the review of scholarship. During times of rapid organizational change, "the use of dialogue, discourse, or conversation is a prominent theme" and "dialogical communication is a process through which change can occur" [11].

One of the disciplines needed for a sustainable learning organization, according to Senge [12], is the art of dialogue. Senge contended that dialogue was an essential element to team functioning during times of change, in that it allowed the group to think insightfully about the complex situation and helped to innovate and coordinate action [12]. The art of dialogue as a form of communication allowed organizations to see the problem from multiple vantage points [12].

Harper and Stein [13] suggested that one of the best ways to handle rapidly changing complex and chaotic problems was through dialogue. However, Harper and Stein [13] and Putman [14] stated that the practice of dialogue required a form of leadership that differed from the traditional definition. It was a form of leadership that focused on the "autonomous individual person" [13] and practiced civility, engagement, and community [14]. The theme of dialogue goes hand in hand with an organizational style that is collaborative and relational [11]. Senge (as cited in Hickman [11]) called for "leadership networks" that function "like communities". These leadership networks are highly communicative and require a version of leadership that is both collaborative and relational.

\subsection{Relationships and Collaboration}

The collapse of both Lehman Brothers and the Dow Jones Industrial Average during the month of September in 2008, was a damaging blow to the financial institutions and the stock market. However, the moments that stuck out the most in Tim's memories of their experiences were not necessarily ones of great financial loss, but the collaboration and relationship building that took place during the crisis.

For Tim's organization, relationships were everything, both with the employees, the customers, and other organizations. Tim recalled that the most positive experiences during the recession were the deeper bonds forged between him and other employees and other organizations. During the crisis, the relationships with his co-workers were strengthened. The importance of relationships and the imprint relationships had on Tim's psyche was consistent with the definitions of leadership provided by both Foster [15] and Rost [16]. Foster contended that leadership "does not reside in an individual but in the relationship between individuals" [15]. Rost argued that a new form of leadership was needed for the 21 st century that was an "influence relationship among leaders and followers [16].

Elements of transformational leadership were also seen throughout Tim's story. According to Northouse [17], transformational leadership requires leaders to be strong role models for the beliefs and actions they wish their followers to adapt. Throughout the crisis, Tim said that he portrayed confidence in his organization because of how prepared they were for the collapse. For Tim, it was important to "be visible."

During times of chaos, Hazy [18] argued for a style of leadership that was more collaborative in nature and used less direct authority. From this collaborative perspective, leadership would be more focused on the entangled relationships among all parties involved than it would be about one specific person [18]. Parks [19] stated that leadership during chaos should enable people in order to create together something that works in the situation.

Creating together and collaborating rather than directing and dictating requires a different kind of leadership similar to what Burns [20], Northouse [17], and Rost [16] called for. It requires a relational style of leadership. This relational and transformative style of leadership "fits the needs of today's work groups, who want to be inspired and empowered to succeed in times of uncertainty" [17].

From Tim's point of view, his organization's success was due to the strong relationships he held with both his customers and employees. For Tim, "long-term major commitments" and relationships with other organizations were responsible for their organizational success. Tim touched on the significant increase in his organization's partnerships that came out of the recession phenomenon.

The partnerships, relationships, and collaboration that emerged out of the economic crisis were consistent with what Waddock (as cited in Hickman [11]) called for: "competition and collaboration, with sustainability, are necessary and important to societal — and business - health and success".

As mentioned above, the theme of relational and collaborative leadership goes together with the dialogical organizational element and is also connected to the theme of systems thinking. In making sense of complex issues, and 
during times of change, "when effective collaboration is the aim, developing a shared conceptual 'systems sense' is even more important" (Senge, as cited in Hickman [11]). Senge went on to state that creating a "relational space (to dialogue) can be systematic and purposeful" [11].

\subsection{Ethics, Values, and Truth}

For Tim whose organization survived the collapse, the elements that emerged out of his stories as important were ethics, values, and mission. In the context of this study, the bifurcation point was the experience of the recession.

In a sense, the theme of value sharing and ethics goes hand in hand with the other two themes of communication and relational leadership. Due to the relational nature of the organizational leaders in this study, the leaders felt the need to communicate the truth about the crisis and its implications to those around them.

Leaders who are perceived as being able to create and support an ethical culture in their organizations are those who represent, communicate, and role model high ethical standards, emphasize attention to goals other than economic, engage in "ethics talks," and maintain a long-term view of relationships both within and outside the organization. (Ardichvili, as cited in Hickman [11])

Hay [21] addressed this concept when he spoke about the need for sustainability programs to give attention to ethics. What Hay [21] called for was a more eco-centric ethical approach that considered all stakeholders involved rather than individual stakeholders. These leaders, according to Hay [21], "need to personally embody such morality, while wanting to transform those around them for the betterment of society and the environment as a whole".

Freeman and Auster [22] studied the effects of the financial crisis on leadership and concluded that there was an increase in the importance of values and ethics among leadership. Freeman and Auster [22] connected the relational nature of leaders with the increased desire for values and ethics within their organization. Freeman and Auster argued that responsible leaders should hold to a version of values and ethics similar to that given by Mak and Pless [23], which was:

A specific frame of mind promoting a shift from a purely economistic, positivist and self-interested mindset to a frame of thinking that has all constituents and the common good in mind.

Waddock (as cited in Hickman [11]) noted that leadership in the new corporate era will require "aware leaders that have thought deeply about their own values and vision and, as a result, are prepared for the complex world they must face". Waddock went on to state that this awareness will not lessen the complexity and difficulty of the decisions leaders will be faced with, but it will help them make the right decisions if and when the chaos is high.

\subsection{Crisis as Opportunity}

In my interaction with Tim, there was a deep sense of calmness at the heart of his story. At one point, Tim said that he believed this calmness came from past experiences and the fact that "you can only get yourself worked up so many times." Tim said he now tries to see problems from a positive perspective. Tim interpreted the recession as an opportunity, not a crisis. While he knew it was not going to be an easy experience, he embodied a calm confidence that, if used properly, could result in a stronger and more sustainable business model. Tim had the foresight and discernment to systematically interpret these causes and interconnections and chose the way of ethical, sustainable, and relational business policies over short-term profit. These are the reasons Tim's organization thrived during the worst economic recession since the Great Depression.

\section{Conclusion}

The story of Tim in this case gives one a unique insight into how the Great Recession of 2008 was interpreted and responded to in subjective context within the healthcare industry. The constructed experience by the participant influenced his decisions toward more holistic and relational leadership styles and perspectives that, in turn, impacted the overall organizational systems. Tim attributed his experience of the Great Recession to changes in the way he led and understood his organizations. While both negative and positive experiences were mentioned, there was no question as to whether or not the experience of the recession impacted the way the participants viewed their organizational systems, their leadership, and their overall sense of self.

\section{References}

[1] Pech, R., \& Oakley, K. (2005). Hormesis: an evolutionary "predict and prepare" survival mechanism. Leadership \& Organization Development Journal, 26 (8), 673-687. https://doi.org/10.1108/01437730510633737.

[2] Kaivo-oja, J., Stenvall, J. (2013). Foresight, governance and complexity of systems: On the way towards a pragmatic governance paradigm. European Integration Studies Journal. No. 7.

[3] Shaked, H., \& Schechter, C. (2018). Systems Thinking Among Enrollees in a Principal Preparation Program. Journal of Research on Leadership Education, 13 (3), 259-282. https://doi.org/10.1177/1942775118771384.

[4] Laszlo, E. (1996). A systems view of the world: A holistic vision for our time. Hampton Press. New Jersey.

[5] Meadows, D. (2008). Thinking in systems. Hartland, VT: The Sustainability Institute.

[6] Meadows, D. (1999). Leverage points: Places to intervene in a system. Hartland, VT: The Sustainability Institute.

[7] Weinberg, G. (2001). An introduction to general systems thinking. Dorset House publishing co.

[8] Prigogine, I., \& Stengers, I. (1984). Order out of chaos: Man's new dialogue with nature. New York, NY: Bantam. 
[9] Kirk, P. (1999). Corporate evolution and the chaos advantage. The Systems Thinker, 10 (10), 1-12.

[10] Wilber, K. (1996). A brief history of everything. Boston, MA: Shambhala publishing.

[11] Hickman, G. (2015). Leading organizations: Perspectives for a new era, 3rd ed. Thousand Oaks, CA: Sage.

[12] Senge, P. (1990) The fifth discipline: The art of practice of the learning organization. New York, NY. Doubleday.

[13] Harper, S. \& Stein, S. (2006). Dialogical planning in a fragmented society: Critically liberal, pragmatic, and incremental. New Brunswick, NJ: Rutgers University Publishing.

[14] Putman, R. (1993). Making democracy work: Civic traditions in modern Italy. Princeton, NJ: Princeton University Press.

[15] Foster, W. F. (1989). Toward a critical practice of leadership. Critical Perspectives on Educationall Leadership. pp. 39-62. London, UK: Falmer.
[16] Rost, J. (1993). Leadership for the 21st century. Westport, CT: Praeger.

[17] Northouse, P. (2018). Leadership: Theory and practice. Sage publishing: New York, NY.

[18] Hazy, J. (2008). Toward a theory of leadership in complex systems: Computational modeling explorations. Nonlinear Dynamics, Psychology, and Life Sciences, 12 (3), 281-310.

[19] Parks, S. (2005). Leadership can be taught: A bold approach to a complex world. Boston, MA: Harvard Business School Press.

[20] Burns, J. (1978). Leadership. New York, NY: Harper \& Row.

[21] Hay, R. (2010). The relevance of ecocentrism, personal development and transformational leadership to sustainability and identity. Sustainability Development Journal, 18, 163-171.

[22] Freeman, R. \& Auster, E. (2011). Values, authenticity, and responsible leadership. Journal of business ethics. 98, 15-23.

[23] Maak, T. \& Pless, N. (2006). Responsible leadership. New York, NY: Routledge publishing. 